\title{
Extensive ossification in a pulmonary plasmacytoma
}

\author{
S. G. K I N A RE, G. B. PARULKAR, S. R. PANDAY, A N P. K. SEN \\ From the Department of Surgery, King Edward VII Memorial Hospital, Parel, Bombay 12, India
}

Extramedullary plasmacytomata form an interesting group of tumours, the nature and behaviour of which are still not well understood. The majority of such tumours are situated in the pharynx, upper respiratory tract, and conjunctiva (Hellwig, 1943). Less frequent sites have been the thyroid, intestine, ovary, and kidney. A study of the literature available to us has revealed that so far 18 cases (Ackerman, 1953; Brunn, 1939; Carson, Ackerman, and Maltby, 1955 ; Childress and Adie, 1950; Cotton and Penido, 1952; Gordon and Walker, 1944 ; Hill and White, 1953 ; Kilburn and Schmidt, 1960 ; Kuley and Kuntman, 1951 ; Lane, Krohn, Kolozsi, and Whitehead, 1955 ; Lisovskii and Grindzhiliya, 1962 ; Rambaldi, Odoardi, and Vergine, 1959; Robson and Knudsen, 1959 ; Romanoff and Milwidsky, 1962; Rozsa and Frieman, 1953; Tchertkoff, Lee, and Wagner, 1963 ; Uvarova and Dubrovaskii, 1962 ; Viszlóy and Daróczy, 1960) of pulmonary plasmacytoma ('plasma cell granuloma') have been recorded. The purpose of this report is to detail one more case of pulmonary plasmacytoma featuring extensive new bone formation not noted so far in any reported case.

\section{CASE REPORT}

S. D., a girl aged 10 years, was admitted to King Edward VII Memorial Hospital, Bombay. Her chief complaint was of repeated attacks of unproductive cough starting one year before admission. Cough was not accompanied by fever or pain in the chest. The child had lost weight and become pale. She had also experienced breathlessness on exertion. The past history was not relevant.

Examination revealed a poorly built and nourished child. The finger-nails were pale ; but no clubbing or cyanosis was noticed. There was no lymphadenopathy. The thyroid showed moderate diffuse enlargement. The pulse was palpable in all the extremities. The blood pressure was $94 / 60 \mathrm{~mm}$. $\mathrm{Hg}$.

Examination of the cardiovascular system revealed that the praecordium was bulging slightly. The apex beat was palpable in the left fifth space in the midclavicular line. On percussion the left border of the heart could not be made out because of dullness all over the left side of the chest. The heart sounds were normal. No murmurs were audible.
On examination of the respiratory system the trachea was central. The movements of the left side of the chest were diminished. Tactile vocal fremitus was also diminished on the left side. On percussion the entire left side of the chest was dull, and on auscultation the breath sounds were diminished in intensity and occasional rales were present.

Examination of the abdomen showed that both the spleen and the liver were palpable two fingerbreadths below the costal margin. Other systems were normal.

INVESTIGATIONS Examination of the urine showed no Bence Jones proteins.

The haemoglobin was $9.8 \mathrm{~g} / 100 \mathrm{ml}$, R.B.C. $3,800,000 /$ c.mm., W.B.C. $4,200 /$ c.mm., neutrophils $54 \%$, lymphocytes $36 \%$, eosinophils $6 \%$, monocytes $4 \%$. The E.S.R. (Westergren method) was $44 \mathrm{~mm}$. at the end of one hour. Bone marrow examination showed normoblastic hyperplasia. Myeloid series was normal. No increase in plasma cells was noted. Total proteins $7 \mathrm{~g} . / 100 \mathrm{ml}$., albumin $3.8 \mathrm{~g} . / 100 \mathrm{ml}$., globulin $3 \cdot 2 \mathrm{~g} . / 100 \mathrm{ml}$. Icteric index 3 units. Bilirubin $0 \cdot 2 \mathrm{mg}$./ $100 \mathrm{ml}$. Van den Bergh test was negative. Blood cholesterol $216 \mathrm{mg} . / 100 \mathrm{ml}$. Blood non-protein nitrogen $24 \mathrm{mg}$. $/ 100 \mathrm{ml}$. Urea nitrogen $9 \mathrm{mg}$./100 ml. Serum calcium $10 \mathrm{mg} . / 100 \mathrm{ml}$. Serum phosphorus $2 \cdot 8 \mathrm{mg}$. $/ 100 \mathrm{ml}$., alkaline phosphatase $3 \cdot 2$ B.U.

Radiographs of the chest showed a diffuse opacity occupying the major part of the left lung field (Fig. 1). Large areas of calcification were seen in the lower part of this opacity. There was no mediastinal shift. The heart was normal. Bronchography showed extrinsic pressure on the lingular and lower lobe bronchus. Bronchoscopy did not reveal any endobronchial growth. Radiographs of all the other bones showed no abnormality. The electrocardiogram showed incomplete right bundle branch block.

A clinical diagnosis of intrapulmonary teratoma or hamartoma was considered, and an exploratory thoracotomy was made through the left sixth rib bed under general anaesthesia. On opening the pleural cavity a large tumour, $10 \times 8 \mathrm{~cm}$., was seen occupying the left chest cavity. The tumour was intrapulmonary and was densely adherent to the parietal pleura and pericardium. The tumour was fleshy in places and bony hard in others. A frozen section biopsy of the tumour at this stage suggested a diagnosis of pulmonary plasmacytoma, and it was decided to proceed with left pneumonectomy which was carried out after intrapericardial ligation of the pulmonary artery and veins. The patient made an uneventful recovery and 
was discharged from the hospital two weeks after surgery. At the time of discharge she was asymptomatic, and the liver and spleen were no longer palpable.

PATHOLOGY The specimen of the lung removed at operation weighed $310 \mathrm{~g}$. The upper lobe of the lung was almost spherical, on account of the tumour, but the lower lobe had maintained its shape. The interlobar fissure was almost obliterated. The pleural surface showed multiple vascular fibrous adhesions and a patch of adherent pericardium. On palpation a mass was felt within the lung substance which was extending from the apex to the base. The upper half of the tumour was firm in consistency but the lower half was stony hard. The cut surface of the lung showed a tumour mass $10 \times 8 \times 6 \mathrm{~cm}$. in size almost completely replacing the lung tissue and leaving only a thin rim of the normal lung tissue at the periphery. The upper half of the tumour was firm and fleshy, greyish white in colour and shuwed a whorled appearance. It was well defined; but no capsule could be detected. The lower half of the tumour was ill-defined, yellowish white in colour, and formed mainly of bony tissue (Fig. 2).

HISTOPATHOLOGY Sections from the fleshy portion showed a more or less uniform structure. The lung parenchyma was completely destroyed except for a

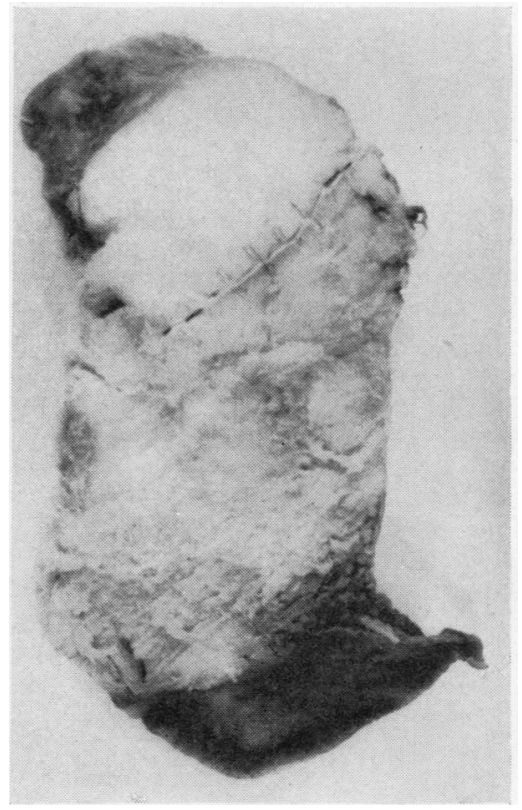

FIG. 2. The cut surface of the lung. The tumour was soft and fibrous in the upper portion and bony in the lower portion. 


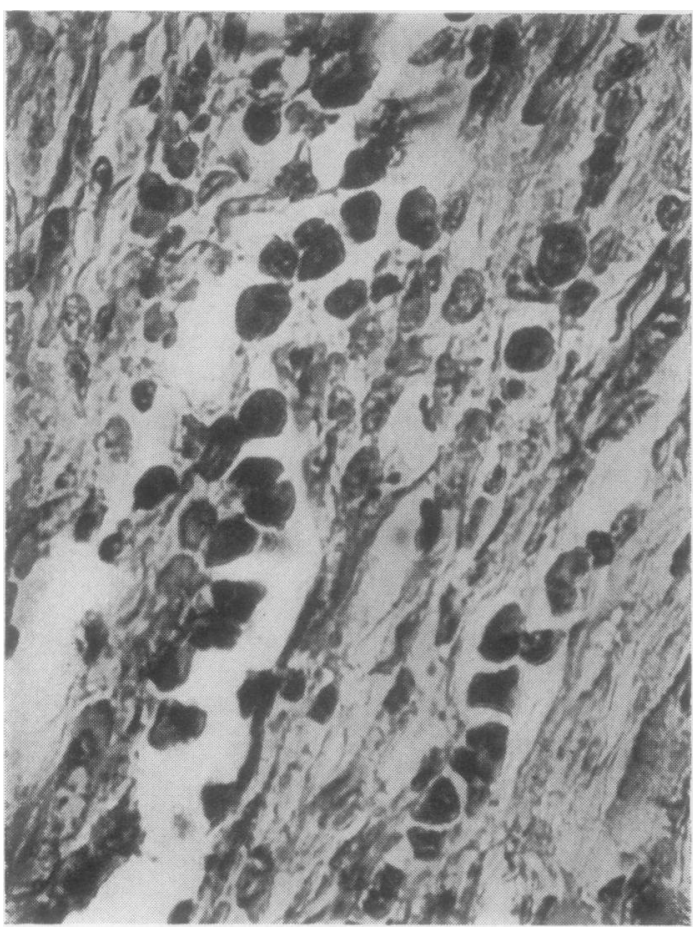

FIG. 3. Photomicrograph of the tumour (soft portion) showing characteristic plasma cells.

few small intact bronchioles. The tumour consisted of sheets and groups of plasma cells supported by a network of fibrous tissue (Fig. 3). The amount of fibrous tissue varied from section to section. In some it was hardly discernible, whereas in others it consisted of thick hyalinized bundles. The tumour in general was not very vascular. Some of the capillaries showed thickened hyalinized walls. The majority of cells were polyhedral or ovoid in shape but some were almost spindle-shaped. The cytoplasm was slightly basophilic, and the nuclei were characteristically eccentric with cartwheel-like chromatin distribution. No Russel bodies were found. In places aggregates of lymphoid cells were seen. Sections taken from the bony part showed no other tissue than newly formed bone deposited on hyaline pink ground substance (Fig. 4). Some showed small groups of plasma cells. The presence of pink hyaline ground substance and thickened capillaries suggested amyloid deposition, but no amyloid could be demonstrated by special stains.

\section{DISCUSSION}

Opinion is divided regarding the origin of the pulmonary plasmacytoma. Kilburn and Schmidt (1960) believe that intrathoracic plasmacytomata

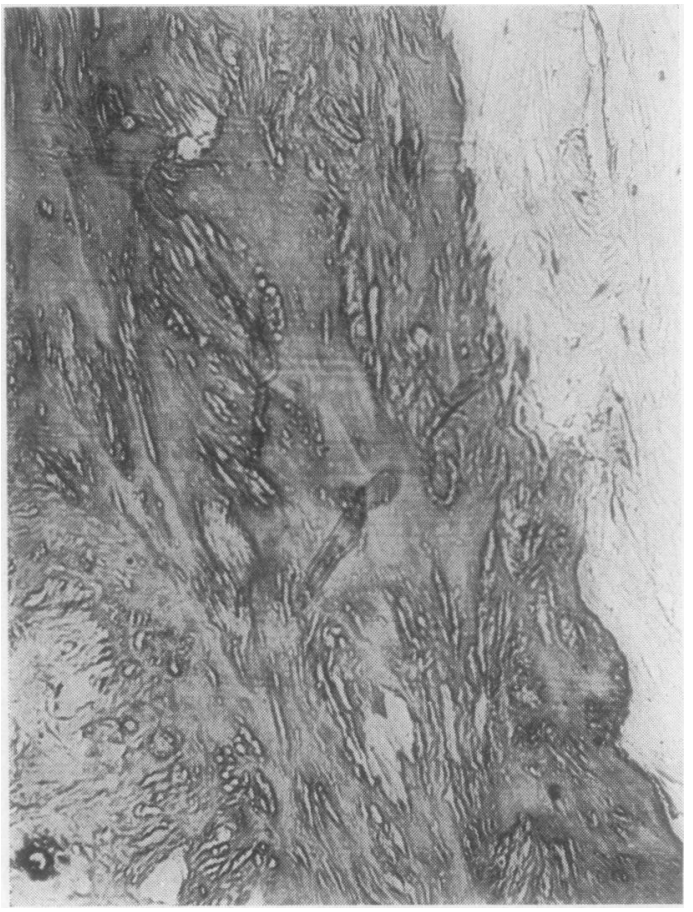

FIG. 4. Photomicrograph of the tumour (bony portion) showing ossification.

usually originate in the mediastinal and hilar lymph nodes. They consider that the classification of these tumours into those of mediastinal origin and those of pulmonary origin is artificial. In our patient the mediastinal and hilar lymph nodes did not reveal any evidence of plasmacytoma.

Several theories have been put forward to explain the pathogenesis of this curious entity. Brunn (1939) has named it a lung tumour of contradictory histopathology. Lane et al. (1955) have suggested the myeloid theory of origin. Tchertkoff et al. (1963) think that it is a non-neoplastic granulomatous condition in which there is a predominance of plasma cells. Umiker and Iverson (1954) call it 'post-inflammatory tumour of the lung' and consider it a result of a post-inflammatory reparative process. Gordon and Walker (1944) have suggested that solitary pulmonary granulomata represent a low-grade malignant tumour. The infiltrative nature of the lesion and its reported recurrence (Childress and Adie, 1955) and occasional spread to distant organs (Robson and Knudsen, 1959) are suggestive of neoplasm. We consider that some of the cases of plasmacytoma reported in the literature may be plasma cell 
granulomata and it may be difficult to distinguish the two types of lesion. The presence of no type of inflammatory cell other than plasma cells, and the infiltrative character and complete destruction of the normal architecture of the organ involved, as are present in our case, are points in favour of its neoplastic origin. The presence of other mesenchymal cells such as mononuclears, fibroblasts, and giant cells together with plasma cells, as reported by Lane et al. (1955) and Umiker and Iverson (1954), indicate a granulomatous nature.

The relation of these tumours to similar tumours of the bone, namely multiple myelomata and solitary myeloma, is intriguing. Jackson, Parker, and Bethea (1931) and Carson et al. (1955) prefer to group these tumours as myelomata, but they differ in many respects from medullary myelomata though extensive pulmonary involvement in myelomatosis has been reported by Freeman (1961). Multiple myelomata is a disease of advanced age with a predilection for men and is usually associated with changes in the serum protein pattern and the appearance of Bence Jones proteins in the urine. The deposition of amyloid is a common feature of multiple myelomata. None of the extramedullary plasmacytomata show any of these features, and they show no preference for any age or sex.

None of the reported cases of pulmonary plasmacytoma, except possibly the one reported by Robson and Knudsen (1959) in which stomach, bone, spleen, and lymph node were also involved, showed any distant metastasis. Childress and Adie (1950) are the only authors who have reported a recurrence of pulmonary plasmacytoma. Though the number of these tumours showing a recurrence or distant metastases is small, in the absence of bone marrow examination in some of the cases reported and without long-term follow-up studies of these cases it is not possible to draw any conclusion regarding distant spread and local recurrence.

A study of the available clinical data of the reported cases shows that the lesion is seen in both sexes with almost equal frequency and in all ages. The duration of symptoms varies between one and five years. A few patients are asymptomatic and are detected during a routine radiographic examination. Cough, chest pain, and dyspnoea are the most prominent symptoms. Fever is present in only a few patients. The clinical signs are absent in early lesions. Later, signs of atelectasis and consolidation are present. The pre-operative diagnosis is difficult but is suspected where the mass, in spite of being situated close to the hilum, shows a constant negative cytology for cancer cells, and where other infective lesions can be excluded. Kuley and Kuntman (1951) had carried out a needle aspiration of the tumour to make the diagnosis. Exploratory thoracotomy and frozen section biopsy are the most dependable methods of diagnosing a pulmonary plasmacytoma.

Pulmonary resection together with excision of its local extension seems to be the most rational treatment in view of the low-grade malignancy of the tumour. Radiotherapy may be useful for local recurrence or distant spread.

The present case of plasmacytoma shows a few interesting features. The growth has practically destroyed and replaced the whole lung like a malignant tumour. In most of the reported cases the lesion presented a benign appearance and was usually capsulated. Extensive new bone formation was a remarkable feature and has not been described in any of the tumours reported so far. Half of the tumour was pure bone. Amyloid in plasmacytomata could predispose to bone deposition, but no amyloid could be demonstrated in this tumour. No other explanation can be given for this extensive bone formation, except that it occurred as a result of metaplasia of the fibrous ground substance of the tumour. The absence of other tissues in the tumour rules out a diagnosis of teratoma or hamartoma.

\section{SUMMARY}

A case of pulmonary plasmacytoma exhibiting the unique feature of extensive bone formation is reported. The pathogenesis, clinical features, and treatment of this lesion are briefly discussed. The explanation for the ossification in the present tumour is presented.

We wish to express our gratitude to Professor N. M. Purandare, Professor Y. M. Bhende, and Dr. M. V. Sirsat for their help in the interpretation of the histopathological sections.

\section{REFERENCES}

Ackerman, L. V. (1953). Surgical Pathology, p. 208. Mosby, St. Louis. Brunn, H. (1939). Two interesting benign lung tumors of contradictory histopathology. J. thorac. Surg., 9, 119.

Carson, C. P., Ackerman, L. V., and Maltby, J. D. (1955). Plasma cell myeloma. Amer. J. clin. Path., 25, 849.

Childress, W. G., and Adie, G. C. (1950). Plasma cell tumors of the mediastinum and lung. J. thorac. Surg., 19, 794.

(1955). Recurrent plasmacytoma of the lung. Ibid., $29,480$. Cotton, B. H., and Penido, J. R. F. (1952). Plasma cell tumors of the lung. Dis. Chest, 21, 218.

Freeman, Z. (1961). Myelomatosis with extensive pulmonary involvement. Thorax, 16, 378 .

Gordon, J., and Walker, G. (1944). Plasmacytoma of the lung. Arch. Path., 37, 222. 
Hellwig, C. A. (1943). Extramedullary plasma cell tumors as observed in various locations. Ibid., 36, 95 .

Hill, L. D. III., and White, M. L., Jr. (1953). Plasmacytoma of the lung. J. thoiac. Surg., $25,187$.

Jackson, H., Jr. Parker, F., Jr., and Bethea, J. M. (1931). Studies of diseases of the lymphoid and myeloid tissues. II. Plasmatocytomata and their relationship to multiple myeloma. Amer. J. med. mata and their
Sci., 181, 169.

Sci., 181, 169 .
Kilburn, K. H., and Schmidt, A. M. (1960). Intrathoracic plasmacytoma. Arch. intern. Med., 106, 862 .

Kuley, M., and Kuntman, O. (1951). A case of plasmacytoma of the lung. Dis. Chest, 19, 227.

Lane, J. D., Krohn, S., Kolozsi, W., and Whitehead, R. E. (1955). Plasma cell granuloma of the lung. Ibid., 27, 216.

Lisovskii, A. J., and Grindzhiliya V. I.(1962). A case of plasmacytoma of the lung. Khirurgiya (Mosk.), 38, No.8, p. 129. (In Russian.)
Rambaldi, M., Odoardi, G. B., and Vergine, A. (1959). Plasmocitoma extradosseo a sede polmonare. Rif. med., 73, 1465.

Robson, A. O., and Knudsen, A. (1959). Plasmacytoma of lung and stomach. Brit. J. Dis. Chest, 53, 62.

Romanoff, H., and Milwidsky, H. (1962). Primary plasmacytoma of the lung. Ibid., 56, 139.

Rozsa, S., and Frieman, H. (1953). Extramedullary plasmacytoma of the lung. Amer. J. Roentgenol., 70, 982.

Tchertkoff, V., Lee, B. Y., and Wagner, B. M. (1963). Plasma cell granuloma of lung. Dis. Chest, 44, 440.

Umiker, W. O., and Iverson, L. L. (1954). Postinflammatory "tumors" of the lung. $J$. thorac. Surg., 28, 55.

Uvarova, O. A., and Dubrovaskii, A. V. (1962). Plasmacytoma of the lung. Klin. Med. (Mosk.), 40, No. 4, p. 127. (In Russian.)

Viszlóy, K., and Daróczy, G. (1960). Plasmocytoma of the lung. Orv. Hetil., 101, 1033. (In Hungarian.) 